\title{
Cloning and Regulation of Expression of the Rat Kidney Urea Transporter (rUT2)
}

\author{
Craig P. Smith, * Wen-Sen Lee, ${ }^{*}$ Sonia Martial, ${ }^{\ddagger}$ Mark A. Knepper, ${ }^{\varsigma}$ Guofeng You, * Jeff M. Sands, ${ }^{\ddagger}$ \\ and Matthias A. Hediger* \\ * Renal Division, Department of Medicine, Brigham and Women's Hospital and Harvard Medical School, Boston, Massachusetts 02115; \\ ${ }^{\ddagger}$ Renal Division, Department of Medicine, Emory University School of Medicine, Atlanta, Georgia 30322; and ${ }^{\S}$ Laboratory of Kidney \\ and Electrolyte Metabolism, National Heart, Lung, and Blood Institute, National Institutes of Health, Bethesda, Maryland 20892
}

\begin{abstract}
In mammals, urea is the predominant end-product of nitrogen metabolism and plays a central role in the urinaryconcentrating mechanism. Urea accumulation in the renal medulla is critical to the ability of the kidney to concentrate urine to an osmolality greater than systemic plasma. Regulation of urea excretion and accumulation in the renal medulla depends on the functional state of specialized phloretin-sensitive urea transporters. To study these transporters and their regulation of expression we isolated a cDNA which encodes the rat homologue (rUT2) of rabbit UT2 (You, G., C. P. Smith, Y. Kanai, W.-S. Lee, M. Stelzner, and M. A. Hediger, et al. Nature (Lond.). 1993. 365:844-847). Rat UT2 has $88 \%$ amino acid sequence identity to rabbit UT2 and $64 \%$ identity to the recently cloned human erythrocyte urea transporter, HUT11 (Olives, B., P. Neav, P. Bailly, M. A. Hediger, G. Rousselet, J. P. Cartron, and P. Ripoch J. Biol. Chem. 1994. 269:31649-31652). Analysis of rat kidney mRNA revealed two transcripts of size 2.9 and $4.0 \mathrm{~kb}$ which had spatially distinct distributions. Northern analysis and in situ hybridization showed that the 4.0-kb transcript was primarily responsive to changes in the protein content of the diet whereas the 2.9-kb transcript was responsive to changes in the hydration state of the animal. These studies reveal that the expression levels of the two rUT2 transcripts are modulated by different pathways to allow fluid and nitrogen balance to be regulated independently. Our data provide important insights into the regulation of the renal urea transporter UT2 and provide a basis on which to refine our understanding of the urinary concentrating mechanism and its regulation. (J. Clin. Invest. 1995. 96:1556-1563.) Key words: urea - membrane transport protein - nitrogen metabolism $\cdot$ urinary concentrating mechanism $\cdot$ colon
\end{abstract}

\section{Introduction}

Carrier-mediated urea transport plays an important role in nitrogen balance and water conservation (1). Urea formed in the

Address correspondence to Matthias A. Hediger, Renal Division, Brigham and Women's Hospital, 75 Francis Street, Boston, MA 02115. Phone: 617-732-5850; FAX: 617-732-6392. Wen-Sen Lee's current address is Cardiovascular Biology Laboratory, Harvard School of Public Health, Boston, MA 02115.

Received for publication 23 December 1994 and accepted in revised form 2 June 1995.

J. Clin. Invest.

(C) The American Society for Clinical Investigation, Inc.

0021-9738/95/09/1556/08 \$2.00

Volume 96, September 1995, 1556-1563 liver via the urea cycle enters the circulation and is freely filtered by the kidney. The amount of filtered urea excreted is regulated and depends on the physiological status of the animal. Protein restriction causes a decrease in the fraction of filtered urea excreted (2-4). This response reduces the loss of nitrogen from the body and serves to maintain plasma urea concentration, which would otherwise decrease in direct proportion to the lowering of nitrogen intake $(2,3,5-7)$. Micropuncture studies have suggested that the decrease in urea excretion with low protein intake is a result of increased urea absorption from the collecting ducts $(6,8,9)$. In agreement, measurements in isolated perfused inner medullary collecting ducts (IMCD) ${ }^{1}$ show an increase in phloretin-sensitive urea transport in the initial IMCD after dietary protein restriction $(7,10)$.

Regulation of urea transport forms an integral part of the urinary concentrating mechanism. During antidiuresis, increased plasma vasopressin stimulates a rapid increase in urea transport in the IMCD allowing urea to enter the medullary interstitium (11). Increasing urea transport in the IMCD in conjunction with $\mathrm{Na}, \mathrm{K}, 2 \mathrm{Cl}$ cotransport in the thick ascending limb of the loop of Henle (12) enables the establishment and maintenance of the hypertonic medulla which, in turn, provides the osmotic gradient required for water reabsorption $(13,14)$. Urea absorbed in the IMCD is furthermore secreted into thin ascending and descending limbs and descending vasa recta in a process called urea recycling. This recycling pathway limits urea dissipation from the inner medulla allowing the maintenance of the corticopapillary osmotic gradient. The IMCD (15) and the descending vasa recta $(16,17)$ have been recently shown to contain phloretin-sensitive urea transporters.

We have isolated by expression cloning in Xenopus oocytes a cDNA coding for the vasopressin-regulated urea transporter (18) which had been previously characterized by Knepper and colleagues using in vitro perfused tubules $(1,11,15)$. Recently, Ripoche and colleagues isolated a cDNA from a human bone marrow cDNA library coding for the human erythrocyte urea transporter (HUT11) (19). The library screening strategy they used to isolate this cDNA was based on the cDNA sequence of rabbit UT2. HUT11 has $63 \%$ amino acid identity with rabbit UT2 and has functional characteristics which are similar to UT2.

Since little is known about the regulation of urea transporters although they play a central role in nitrogen and water homeostasis a major goal of this study was to isolate a cDNA encoding the rat isoform of rabbit UT2 and to use this as a probe for Northern analysis and in situ hybridization to determine the

1. Abbreviations used in this paper: IMCD, inner medullary collecting duct; ISOM, inner stripe of the outer medulla. 
regulation of rat UT2 (rUT2) mRNA expression in kidneys from animals maintained at different physiological states.

\section{Methods}

Clones were isolated from a nonamplified rat inner medulla $\lambda \mathrm{gt} 22 \mathrm{a}$ cDNA library. Approximately 300,000 clones were screened using a gel-purified, ${ }^{32}$ P-labeled ( ${ }^{77}$ QuickPrime; Pharmacia Biotech Inc., Piscataway, NJ) rabbit UT2 cDNA. Hybridization was at $37^{\circ} \mathrm{C}(50 \%$ formamide) and the final wash was in $0.1 \times$ SSC $-0.1 \%$ SDS at $40^{\circ} \mathrm{C}$. Initial screening yielded 32 clones, out of which a $2.9 \mathrm{~kb}$ cDNA was isolated and subcloned into the Not1/Sal1 site of pSPORT1. Both strands of the cDNA clone were sequenced by the dideoxy-sequencing method using Sequenase V2.0 DNA sequencing kit (USB Biologicals, Cleveland, $\mathrm{OH}$ ).

cRNA was synthesized in vitro and microinjected ( $50 \mathrm{ng}$ ) into collagenase treated and manually defolliculated Xenopus oocytes, as previously described (20). After incubation in Barth's solution for $3 \mathrm{~d}$ at $18^{\circ} \mathrm{C}$, oocytes were preincubated in $200 \mathrm{mM}$ mannitol, $2 \mathrm{mM} \mathrm{KCl}, 1$ $\mathrm{mM} \mathrm{MgCl}, 1 \mathrm{mM} \mathrm{CaCl}, 10 \mathrm{mM}$ Hepes buffer, $5 \mathrm{mM}$ Tris, $\mathrm{pH} 7.4$, for $1 \mathrm{~h}$. To measure urea uptake, $2.7 \mu \mathrm{Ci}\left[{ }^{14} \mathrm{C}\right]$ urea/ml and $1 \mathrm{mM}$ urea were added to the preincubation solution. Unlabeled urea was freshly deionized before use by passing through an ion-exchange column (AG501-X8(D), 20-50 mesh; Bio-Rad Laboratories, Richmond, CA). After uptake, oocytes were washed with ice-cold uptake solution containing $1 \mathrm{mM}$ unlabeled urea, dissolved in $10 \%$ SDS, and the radioactivity was measured by scintillation counting. Inhibition of $\left[{ }^{14} \mathrm{C}\right]$ urea uptake by $0.35 \mathrm{mM}$ or $0.70 \mathrm{mM}$ phloretin was measured by addition of phloretin to the preincubation solution $15 \mathrm{~min}$ before addition of $\left[{ }^{14} \mathrm{C}\right]-$ urea as previously described $(18)$. Uptake of $\left[{ }^{14} \mathrm{C}\right]$ urea $(1 \mathrm{mM})$ was also measured in the presence of $50 \mathrm{mM}$ mannitol and $150 \mathrm{mM}$ thiourea (18). cRNA was translated in vitro using a rabbit reticulocyte lysate system (Promega Corp., Madison, WI) as previously described (21). Analysis was by SDS-PAGE using a $10 \%$ acrylamide gel.

To study the regional distribution of rUT2 mRNA in the kidney, poly $\mathrm{A}^{+}$RNA was isolated from microdissected regions of the kidney (see Fig. 3) by the guanidine isothyocyanate method using cesiumtrifluoroacetic acid followed by oligo(dT)-cellulose column chromatography (Collaborative Biochemical Products, Bedford, MA). Poly $\mathrm{A}^{+}$ RNA ( $3 \mu \mathrm{g} /$ lane) was separated in a $1 \%$ agarose gel in the presence of $2.2 \mathrm{M}$ formaldehyde and transferred to nylon filters. Filters were probed using a ${ }^{32} \mathrm{P}$-labeled full length random primed rUT2 $\mathrm{cDNA}$ probe and hybridized at $42^{\circ} \mathrm{C}$ (50\% formamide). Final washing was in $0.1 \times$ SSC- $0.1 \%$ SDS at $65^{\circ} \mathrm{C}$.

Manipulation of dietary protein content. To study the effect of changing the dietary protein content on the pattern of UT2 mRNA expression, groups of pathogen-free male Sprague-Dawley rats were given free access for 4 wk to water and either a normal diet containing $18 \%$ protein (National Institutes of Health [NIH]-31 diet) or a low protein diet containing $8 \%$ protein (NIH-31LP diet). The low protein diet was isocaloric with the $18 \%$ protein diet and was supplemented with methionine, lysine, calcium, and phosphate to match levels in the normal diet. The low protein diet was the same as that used by Isozaki et al. $(7,10)$ and has been shown to cause a significant decrease in blood urea nitrogen, urinary urea excretion rate, and prevent malnutrition (10).

Manipulation of the hydration state. To study the effect of changing the hydration state on the pattern of expression of UT2 mRNAs in the kidney, groups of pathogen-free male Sprague-Dawley rats were treated as follows: $(a)$ water restricted; rats had free access to food but water was restricted to $10 \mathrm{ml} /$ day for $3 \mathrm{~d}$. (b) Water diuretic; rats had free access to water containing $10 \%$ glucose without additional food for 3 d. (c) Water diuretic then water restriction, rats had free access to water containing $10 \%$ glucose without additional food for $3 \mathrm{~d}$, then no water but free access to food for $2 \mathrm{~d}$. Control Rats were given free access to food and water. These treatments have been previously found to result in significant changes in urine osmolality and not to cause glucosuria or hyperglycemia (22).
Kidneys which were to be used for Northern analysis were removed and immediately frozen in liquid nitrogen. Kidneys destined to be used for in situ hybridization were fixed with $4 \%$ paraformaldehyde and stored at $-80^{\circ} \mathrm{C}$. Total RNA was isolated from whole kidneys by the guanidine isothyocyanate method using cesium-trifluoroacetic acid, or from inner medulla by acid phenol extraction (Tri-reagent; Molecular Research Center, Inc. Cincinnati, $\mathrm{OH}$ ) and separated as described above. Equal loading of total RNA ( $8 \mu \mathrm{g} /$ lane) for Northern analysis was achieved by ensuring that the intensity of the $28 \mathrm{~S}$ and $18 \mathrm{~S}$ ribosomal RNA bands, when stained with ethidium bromide and visualized under UV light, were constant between samples. Filters were hybridized at $48^{\circ} \mathrm{C}$ ( $50 \%$ formamide) with a ${ }^{32} \mathrm{P}$-labeled full length rUT2 cDNA probe and washed in $0.1 \times$ SSC- $0.1 \%$ SDS at $65^{\circ} \mathrm{C}$.

In situ hybridization of rat kidney was performed as previously described (23). Briefly, 7- $\mu \mathrm{m}$ slices were probed with ${ }^{35} \mathrm{~S}$-labeled sense and antisense RNA probes synthesized from the full-length clone (in pSPORT1) after linearization of the plasmid DNA with Not1 or Sal1, using T7 (sense) or SP6 (antisense) RNA polymerase, respectively. RNA probes were hydrolysed for 50-min to generate probes of $\sim 100$ nucleotides. After hybridization, the dried tissue sections were exposed overnight to Hypermax film (Amersham Corp., Arlington Heights, IL). For each treatment, in situ hybridization was performed on the kidney from three separate animals.

\section{Results}

Low stringency screening of a rat kidney medulla cDNA library with the full-length rabbit UT2-cDNA probe yielded a 2,940bp cDNA. Expression studies in Xenopus oocytes (see below) showed that this cDNA encodes a phloretin-sensitive urea transporter. rUT2 cDNA has a polyadenylation sequence (ATTAAA) at position 2898 , an open reading frame from nucleotides 928 to 2118 and encodes a 397 residue protein which has $88.1 \%$ amino acid identity with rabbit UT2 (Fig. $1 a$ ) and $64 \%$ identity with HUT11.

In vitro translation of rUT2 cRNA using rabbit reticulocyte lysates gave a protein with an apparent $M_{\mathrm{r}}$ of $40 \mathrm{kD}$ in the absence of, and $45 \mathrm{kD}$ in the presence of canine pancreatic microsomes (Fig. $1 b$ ). This $5-\mathrm{kD}$ shift in $M_{\mathrm{r}}$ was reversed by treatment with endoglycosidase- $\mathrm{H}$ and is indicative of glycosylation at a single site. Fig. $1 c$ is a schematic representation of rUT2 showing a hypothetical topology and the predicted Nglycosylation, cAMP phosphorylation and protein kinase $\mathrm{C}$ sites. rUT2 has two characteristic extended hydrophobic domains (18) shown in Fig. $1 c$.

Injection of rUT2 cRNA into Xenopus oocytes induced an 11-fold increase in the uptake (3 $\mathrm{min})$ of $\left[{ }^{14} \mathrm{C}\right]$ urea $(1 \mathrm{mM})$ compared to water-injected control oocytes (data not shown). Uptake ( $90 \mathrm{~s}$ ) of urea by rUT2 was completely inhibited by $0.70 \mathrm{mM}$ phloretin, $71 \%$ by $0.35 \mathrm{mM}$ phloretin, and $62 \%$ by $150 \mathrm{mM}$ thiourea (Fig. 2). These properties are consistent with those of the vasopressin-regulated urea transporter UT2 (11, 15,18 ).

High stringency Northern analysis showed hybridization of rUT2 cDNA to species at 2.9 and $4.0 \mathrm{~kb}$ in kidney. These transcripts were not detected in colon, ileum, jejunum, duodenum, stomach, skeletal muscle, heart, liver, lung, or brain (data not shown). Fig. 3 shows the distribution of rUT2 mRNA in dissected rat kidney. Strong hybridization is seen at $4.0 \mathrm{~kb}$ in the inner part of the inner medulla, whereas the inner stripe of the outer medulla (ISOM) shows hybridization at $2.9 \mathrm{~kb}$ only. In the outer part of the inner medulla both the 2.9 and $4.0 \mathrm{~kb}$ transcripts are present. In situ hybridization (Fig. $4 c$, control) revealed a strong signal in the ISOM and in the inner part of 
a)

1

Rat MEESSEIKVETNTTRTTWIQSSMIAGGKRVSKALSYITGEMKECGEGLKD

Rabbit ..D.......ASS..S....VA....I.R..G...........

60

80

100

KSPVFQFLDWVLRGTSQVMFVNNPLSGILIVLGLFVQNPWWAISGCLGTI

$\ldots \ldots \ldots \ldots \ldots \ldots \ldots \ldots \ldots \ldots \ldots \ldots \ldots . \ldots \ldots$

120

140

MSTLTALILSQDKSAIAAGLHGYNGVLVGLLMAVFSDKGNYYWWLLLPVI

$\ldots \ldots \ldots \ldots$. . . . . . . . . . . . . D......

160

180

200

VMSMTCPILSSALSTVFSKWDLPVFTLPFNIAVTLYLAATGHYNLFFPTK

....S . . . . . . . . . . . . . . . . . . . . . . . T

220

240

LLQPAVTT PNITWSDVQVPLLLRAI PVGIGQVYGCDNPWTGGIFLVALFV $\ldots \operatorname{VSSV}_{(B)} \ldots \ldots \mathrm{EI} \ldots \ldots \ldots \ldots \ldots \ldots \ldots \ldots$

260

280

300

SSPLICLHAAIGST IGMLAALSIATPFDSIYFGLCGFNSTLACIAIGGMF

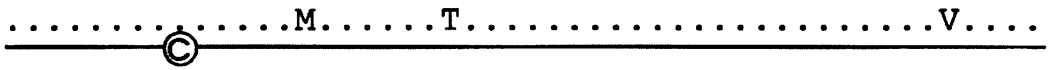

320

340

YVITWQTHLLAIACALFAAYLGAALANMLSVFGL PPCTWPFCLSALTFLL

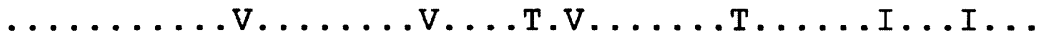

$360 \quad 380 \quad 397$

LTTNNPGIYKLPLSKVTYPEANRI YFLSQEKNRRASMITKYQAYDVS …............ T.Y.T.R... . . .....

b)

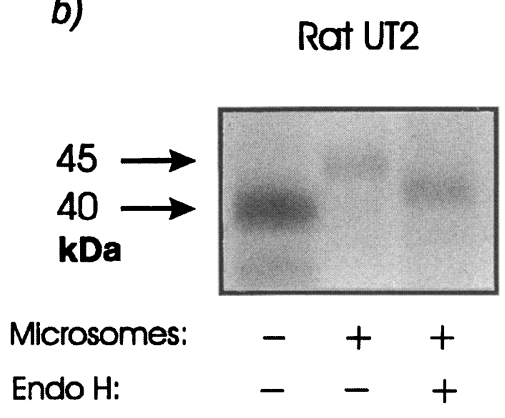

c)

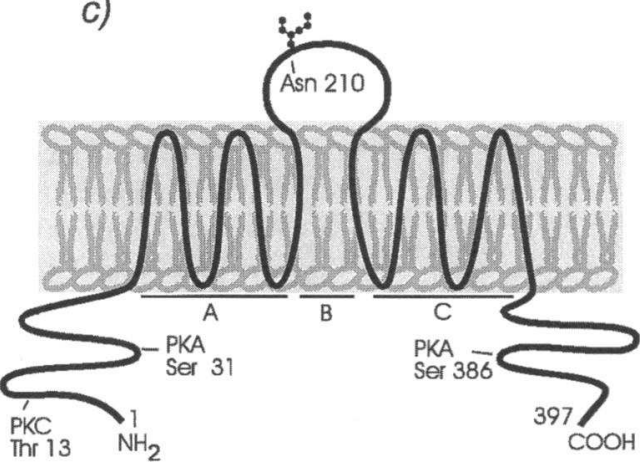

Figure 1. Amino acid sequence and proposed structural model of the rat urea transporter (rUT2). (a) Deduced amino acid sequence. Residues different in rabbit UT2 are shown underneath the sequence. ( $b$ ) Autoradiograph of SDS gel showing in vitro translation products of rUT2 $\mathrm{cRNA}$. Addition of canine pancreatic microsomes and treatment with EndoH are indicated. (c) Schematic representation of a hypothetical topology of rUT2. Regions $A$ and $C$ represent the extended hydrophobic domains and $B$ the hydrophilic domain which contains the glycosylation site. The nucleotide sequence of rUT2 has been deposited in the GenBank under accession No. U09957. the inner medulla corresponding to the 2.9 and $4.0 \mathrm{~kb}$ transcript, respectively. A weaker signal was seen in the outer part of the inner medulla and probably represents a composite of the 2.9 and $4.0 \mathrm{~kb}$ transcripts.

The levels of expression of the two rUT2 transcripts differed considerably between the kidneys of rats fed a low protein diet ( $8 \%$ protein) compared to kidneys from rats fed a normal diet
( $18 \%$ protein). The same pattern was evident in different animals that received the same treatment. Northern analysis showed that low protein diet caused an increase in the $4.0-\mathrm{kb}$ transcript in the inner medulla. There was no detectable change in the levels of the $2.9-\mathrm{kb}$ transcripts in this region of the kidney (Fig. 4, a and b; Table I). The increase in the $4.0-\mathrm{kb}$ transcript was not detected in the RNA from the whole kidney. This was 


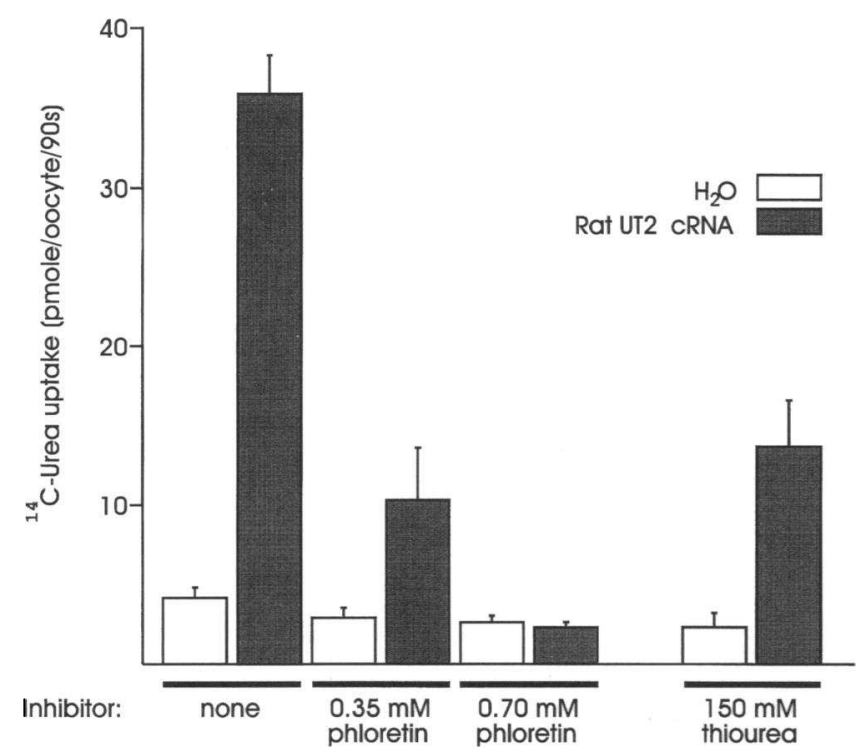

Figure 2. Expression of UT2 in Xenopus oocytes. Filled bars represent oocytes injected with rUT2 cRNA, open bars represent water-injected oocytes. Bars represent mean \pm SEM $(n=5-7)$. (a) Uptake of $1 \mathrm{mM}$ $\left[{ }^{14} \mathrm{C}\right.$ ] urea. $(b)$ Inhibition of $1 \mathrm{mM}\left[{ }^{14} \mathrm{C}\right]$ urea uptake by 0.35 and 0.70 $\mathrm{mM}$ phloretin. (c) Inhibition of $1 \mathrm{mM}\left[{ }^{14} \mathrm{C}\right.$ ] urea uptake by $150 \mathrm{mM}$ thiourea. All uptakes were for $90 \mathrm{~s}$.

most probably due to dilution of the signal by other mRNA species. In situ hybridization revealed that the increased amount of the 4.0-kb transcript was associated with an increase in and spreading towards the outer medulla of the hybridization signal in the inner part of the inner medulla (Fig. $4 c$ ).

Large changes in the amount of rUT2 transcripts were observed in response to alterations in the hydration state (Fig. 5; Table I). After $3 \mathrm{~d}$ of water restriction, the level of the $2.9-\mathrm{kb}$ transcript in the inner medulla and the whole kidney increased (Fig. 5, a and b). In contrast, the level of the 4.0-kb transcript was considerably decreased in the inner medulla whereas there was no discernable change in the level of this transcript in whole kidney RNA, again most probably due to dilution by other mRNA species. In situ hybridization showed that the changes revealed by Northern analysis corresponded to the appearance of a strong signal in the outer part of the inner medulla, an increase in the signal in the ISOM and a decrease in the signal in the papillary tip. The same pattern was evident in different animals that received the same treatment.

Water diuresis, induced by withdrawing access to food and adding $10 \%$ glucose to the drinking water, caused an increase in the amount of the 2.9-kb transcript in whole kidney, but had no effect on the levels of this transcript in the inner medulla (Fig. 5; Table I). No detectable change was observed in the 4.0-kb transcript in whole kidney, but a decrease in the amount of this transcript was evident in inner medullary RNA. In situ hybridization revealed that these changes were associated with an increase in the hybridization signal in the ISOM and a decrease in the signal in the inner medulla. This pattern was consistent in different animals that received the same treatment. We conclude that the increased hybridization signal in the ISOM represents the observed increase in the 2.9-kb transcript and the decreased hybridization signal in the inner medulla represents the observed decrease in the $4.0-\mathrm{kb}$ transcript.

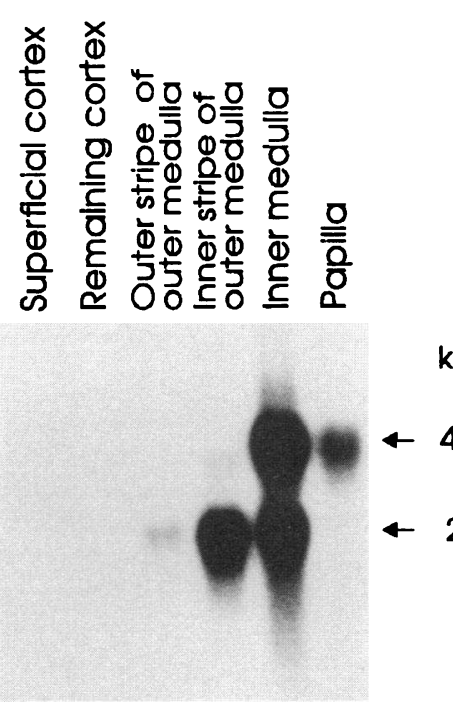

Figure 3. Renal localization of rUT2 by high stringency Northern analysis of dissected kidney. Full length random primed rUT2 cDNA was used as a probe. Filters were hybridized at $42^{\circ} \mathrm{C}$ and final washing was in $0.1 \times$ SSC $-0.1 \%$ SDS at $65^{\circ} \mathrm{C}$. To test whether the coding region of 2.9- and 4.0-kb transcripts were identical we performed reverse transcription (RT) using oligo-dT as a primer followed by PCR amplification $\left(55^{\circ} \mathrm{C}\right.$ primer annealing temperature, 30 cycles of amplification) with a primer set designed to amplify the coding region of the 2.9-kb transcript and predicted to yield a product of $1.2 \mathrm{~kb}$. RT-PCR of papillary tip RNA or RNA from the ISOM gave a product of $1.2 \mathrm{~kb}$ as predicted. Restriction digestion of this product by Alu1, Hinf1, or Pall gave identical restriction patterns (data not shown). In addition, RT-PCR of small bundles of tubules microdissected from the papillary tip or ISOM using identical conditions as described above also gave a 1.2-kb product. Together, these results demonstrated that the 2.9 - and 4.0-kb transcripts have identical or almost identical coding regions.

Water diuresis followed by water restriction caused an increase in the amount of the 2.9-kb transcript in inner medulla and whole kidney (Fig. 5; Table I). A decrease in the level of the 4.0-kb transcript was observed in inner medulla, but not in whole kidney. In situ hybridization revealed the appearance of a signal in the outer part of the inner medulla an increase of the signal in the ISOM and a reduction in the signal in the inner part of the inner medulla. The same pattern was evident in different animals that received the same treatment.

\section{Discussion}

Central to the urinary concentrating mechanism are urea and water transporters located in the plasma membranes of collecting duct cells. Vasopressin stimulates urea and water transport in the terminal IMCD (11). A considerable amount is known about the structure and function of the predominant vasopressinregulated water channel AQP-CD (previously called WHC-CD) (24), whereas, relatively little is known about the vasopressinregulated urea transporter. In the IMCD this transporter allows urea to enter the medullary interstitium by facilitated diffusion (11) (Fig. 6). This process, together with the $\mathrm{Na}, \mathrm{K}, 2 \mathrm{Cl}$ cotransport in thick ascending limbs of the kidney nephron (12) (Fig. 6 ), helps to establish and maintains the corticopapillary osmotic gradient which provides the driving force for water reabsorption (25).

Of equal importance is the role of carrier-mediated urea transport in reabsorption of urea. Feeding rats a diet low in protein is known to cause the fraction of filtered urea excreted by the kidney to decrease. Accompanying this change there is induction of phloretin-inhibitable urea transport in IMCD (7, 10). Salvaging of urea nitrogen from the large intestine is also thought to be important for maintaining nitrogen balance in 

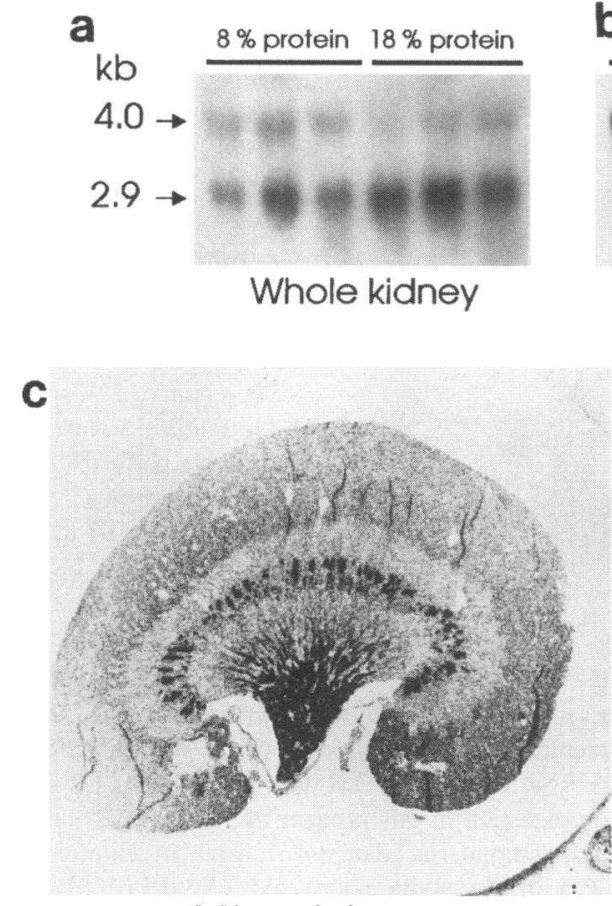

$8 \%$ protein
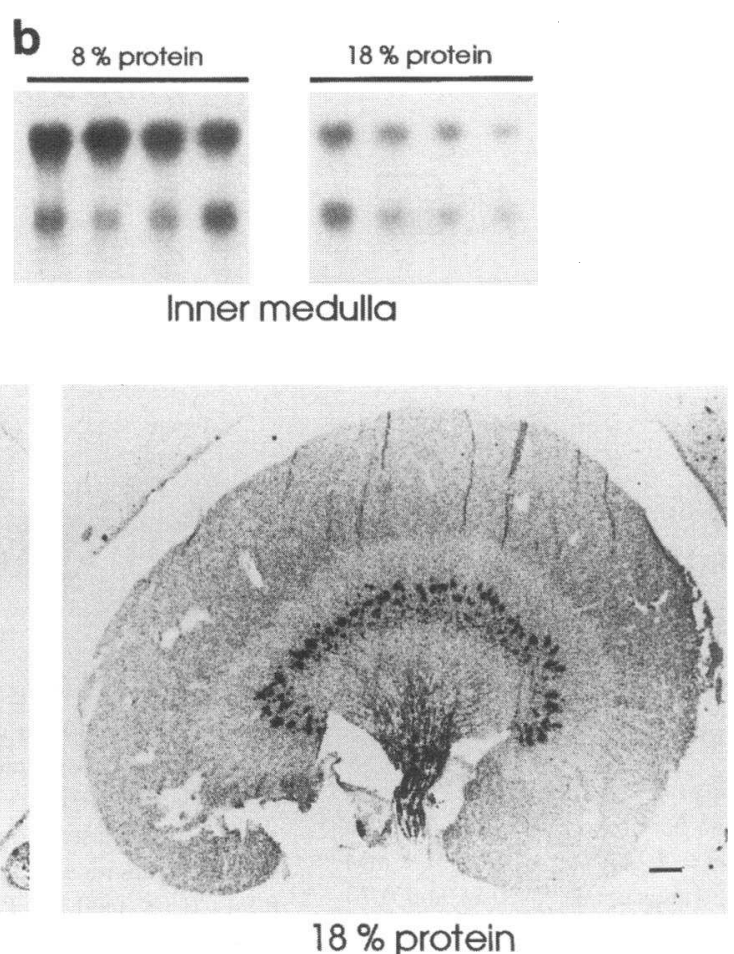

Figure 4. Response to dietary protein deprivation based on high stringency Northern analysis and in situ hybridization. ( $a$ ) Northern analysis of total RNA ( $8 \mu \mathrm{g}$ per lane) from whole kidney $(n=3$ for each treatment). (b) Northern analysis of total RNA ( $8 \mu \mathrm{g}$ per lane) from renal inner medulla ( $n$ $=4$ for each treatment). ( $a$ and $b$ ) Left lanes correspond to rats maintained on $8 \%$ (low) protein diet. Right lanes correspond to rats maintained on $18 \%$ (control) protein diet. Full length random primed rUT2 cDNA was used as a probe. Northern blot filters were hybridized at $48^{\circ} \mathrm{C}$ and final washing was in $0.1 \times$ SSC- $0.1 \%$ SDS at $65^{\circ} \mathrm{C}$. (c) In situ hybridization of kidneys from rats fed; (left) low protein diet, (right) control diet. Autoradiographs show one out of three kidneys analyzed; results were consistent in all three. Bar: $1 \mathrm{~mm}$. animals that normally eat a diet low in protein and in proteindeprived animals $(26,27)$. Phloretin-inhibitable urea transporters are implicated in this process.

Previously, we isolated a cDNA encoding the vasopressinsensitive urea transporter from rabbit kidney (UT2) (18). Here we report the cloning of the rat kidney isoform (rUT2), the tissue distribution of rUT2 and the effect of dietary protein restriction and manipulation of the hydration state on regulation of rUT2 mRNA.

Structure and function of rUT2. Rat and rabbit UT2 are passive transporters characterized by a low affinity for urea. The low affinities of these proteins $(18,28,29)$ together with their unusual kinetic behavior (28) suggest that they constitute a unique class of proteins which conceivably represent a transition between facilitated transporters and channels. The predicted structure of UT2 is furthermore unusual. In contrast to the characteristic pattern of several distinct hydrophobic transmembrane segments interspersed with hydrophilic regions as observed in most plasma membrane transport proteins, or the characteristic $\beta$-barrel structure of the porins of the bacterial outer membrane (30), UT2 has two large extended hydrophobic domains (Fig.

Table I. Summary of Changes in Levels of the 2.9 and 4.0-kb Transcripts in Whole Kidney and in Inner Medulla

\begin{tabular}{lcccc}
\hline & \multicolumn{2}{c}{ Whole kidney } & \multicolumn{2}{c}{ Inner medulla } \\
\hline Transcript & 2.9 & 4.0 & 2.9 & 4.0 \\
$\quad$ Low protein diet & $\leftrightarrow$ & $\leftrightarrow$ & $\leftrightarrow$ & $\uparrow$ \\
Water restricted & $\uparrow$ & $\leftrightarrow$ & $\uparrow$ & $\downarrow$ \\
Water diuretic & $\uparrow$ & $\leftrightarrow$ & $\leftrightarrow$ & $\downarrow$ \\
Water diuretic-water restricted & $\uparrow$ & $\leftrightarrow$ & $\uparrow$ & $\downarrow$ \\
\hline
\end{tabular}

$\uparrow$, increase; $\downarrow$, decrease; $\leftrightarrow$, no change.
$1 \mathrm{c}$ ). It is conceivable that a major portion of the protein is entirely embedded in the membrane.

Cellular localization of rUT2 in kidney. Northern analysis performed on rat tissue clearly demonstrated that there are two different rUT2 transcripts of 2.9 and $4.0 \mathrm{~kb}$ and that these are restricted to the kidney medulla. Two transcripts of 3.0 and 4.0 $\mathrm{kb}$ were observed in rabbit kidney medulla and in contrast to rat a 4.0-kb transcript was also detected in rabbit colon (18).

The presence of a signal in rabbit colon and the absence of a signal in rat colon is of interest. Mammals do not possess urease, the enzyme which catalyzes the hydrolysis of urea into $\mathrm{NH}_{3}$ and $\mathrm{CO}_{2}$. However, the bacteria that reside in the large intestine have urease. It has been proposed that urea diffuses from the blood into the colon where it is broken down by bacteria $(26,27)$. The $\mathrm{NH}_{3}$ released is reabsorbed and used as a nitrogen source for resynthesis of amino acids. This mechanism is thought to be important in herbivorous mammals, such as rabbits, because they eat a diet low in protein. In comparison, rats are omnivorous and consume a diet higher in protein. Our findings indicate that rabbits possess a facilitated urea transport system in colon whereas rats do not. This may represent an adaptation in response to the different amounts of dietary protein consumed by these species.

In the kidney the two transcripts are confined to the renal medulla and occupy spatially distinct regions. The $2.9-\mathrm{kb}$ transcript is predominantly expressed in the ISOM whereas the 4.0$\mathrm{kb}$ transcript is confined to the inner medulla. Both transcripts are present in the outer part of the inner medulla.

This pattern of rUT2 mRNA expression is similar to that found in the rabbit kidney which has a 3.0-kb transcript in the outer medulla and a 4.0-kb transcript in the inner medulla. Amplification of the 4.0-kb transcript in rat kidney by PCR with primers flanking the complete coding region of the $2.9-\mathrm{kb}$ cDNA yielded products of the same size with identical restriction maps suggesting that the two transcripts have the same or 
a)

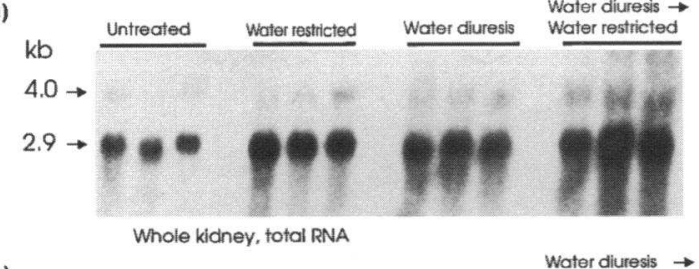

b)

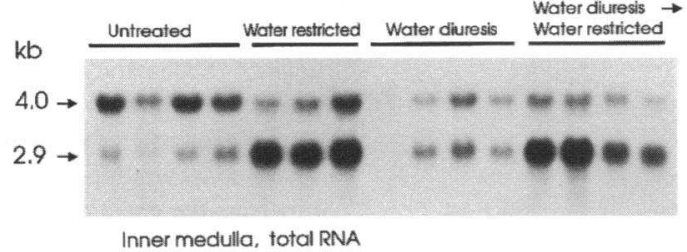

c)

nner medulla, total RNA

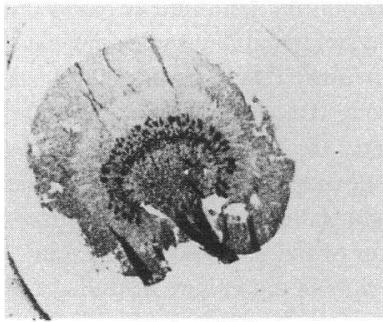

Untreated

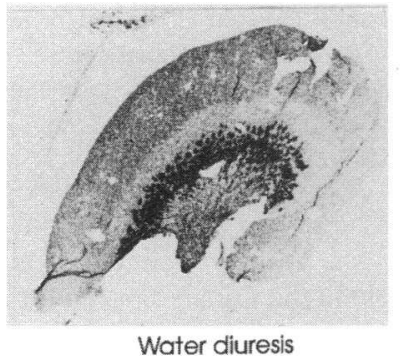

Water diuresis

Figure 5. Response to alteration of the hydration state based on high stringency Northern analysis and in situ hybridization. (a) Northern analysis of total RNA ( $8 \mu \mathrm{g}$ per lane) from whole kidney ( $n=3$ for each treatment). (b) Northern analysis of total RNA ( $8 \mu \mathrm{g}$ per lane) from renal inner medulla ( $n=3-4$ for each treatment). ( $a$ and $b$ ) From left to right lanes correspond to kidneys from control, water-restricted, water-diuretic, and water-diuretic then water-restricted rats. Full length random primed rUT2 cDNA was used as a probe. Northern blot filters were hybridized at $48^{\circ} \mathrm{C}$ and final washing was in $0.1 \times$ SSC- $0.1 \%$ SDS at $65^{\circ} \mathrm{C}$. (c) In situ hybridization of kidneys from rats treated as indicated. Autoradiographs are representative of one out of the three kidneys analyzed for each treatment; results were consistent in all three kidneys. Bar: $1 \mathrm{~mm}$.

a very similar coding region and probably differ at $3^{\prime}$ and/or $5^{\prime}$ untranslated regions (see Fig. 3 legend). This relationship was also found to be true for the two rabbit UT2 transcripts (18).

Based on the present data and those of rabbit UT2 (18) it is reasonable to assume that the hybridization signal revealed by in situ hybridization in the deep part of the inner medulla (4.0-kb transcript) resides in the IMCD (Fig. 6). Physiological studies in the rat IMCD have demonstrated the presence of a phloretin-sensitive transporter on both apical and basolateral plasma membranes of terminal IMCD cells (15, 31). As indicated above, Pallone and colleagues recently reported phloretinsensitive urea transport in the descending vasa recta of the outer medulla $(16,17)$. Studies by Imai and colleagues have demonstrated moderately high urea permeabilities in the thin descending limbs of the short loop nephrons of the outer medulla suggesting the presence of urea transporters $(1,32)$. However, phloretin sensitivity in this segment has not been established. The presence of the 2.9-kb transcript in the outer medulla agrees well with these findings and suggests that rUT2 resides in the descending vasa recta and/or in thin descending limbs of short loops of henle (Fig. 6). Single segment localization of UT2 mRNA and immunocytochemistry will be necessary to confirm the actual sites of rUT2 expression.

Response to dietary protein restriction. Consistent with the findings that dietary protein restriction causes a decrease in the fraction of filtered urea excreted and an associated increase of phloretin-inhibitable urea transport in the IMCD, our data show that feeding a low protein diet induces an increase in the 4.0$\mathrm{kb}$ transcript which is associated with an increase in intensity and a spreading towards the outer medulla of the hybridization signal revealed by in situ hybridization (Fig. $4 c$ ) (7). We conclude therefore that the increase in the 4.0-kb transcript in the inner medulla is associated with an increase of functional urea transporters in IMCD cells. Dietary protein restriction has been found to affect in a coordinated manner the mRNA and protein levels of several enzymes involved in or associated with urea synthesis such as hepatic glutaminase and carbamyl phosphate synthetase $(33,34)$. Factors such as glucagon and dexamethasone have been found to bring about coordinated induction of urea cycle enzymes (35). Whole animal studies suggested that the effect of dietary protein restriction on urea excretion is due to glucocorticoids (2). Thus, glucocorticoids may contribute to long-term regulation of rUT2.

The physiological role of the adaptive changes of mammalian kidney in response to low protein diet are not clear although they appear to be present in the few species that have been tested $(2,3)$. Since in rats we found no evidence of urea transport in colon, implying that salvaging of urea nitrogen from colon does not occur, it is unlikely that the renal changes represent an adaptation geared at preserving nitrogen balance. The changes may, however, function to preserve blood urea concentrations so as to maintain a reserve of urea to enable urine to be concentrated, should the need arise.

Responses to manipulation of the hydration state. Little is known about the regulation of urea transport in response to chronic changes in the hydration state. In the present study, water restriction was found to induce an increase in the level of the 2.9-kb transcript. This corresponded to a large increase in the hybridization signal in the inner medulla and the ISOM. Furthermore, the amount of $4.0-\mathrm{kb}$ transcript decreased in the inner medulla. In contrast to these results is the increase of the 4.0-kb transcript in the inner medulla induced by low protein diet. Recently, the expression levels of several other proteins and their mRNAs have been found to be regulated in response to restriction of water intake. For example, large increases in expression of the vasopressin-regulated water channel AQP-CD occurs in rat collecting ducts in response to thirsting (36) and vasopressin infusion (37). Furthermore, in response to hypertonicity, there is up-regulation of proteins such as aldose reductase and osmolyte transporters which regulate the cellular levels of organic osmolytes in the renal medulla $(22,38)$. The mechanisms of these regulatory processes are under investigation and remain largely unknown. However, it seems likely that mecha- 


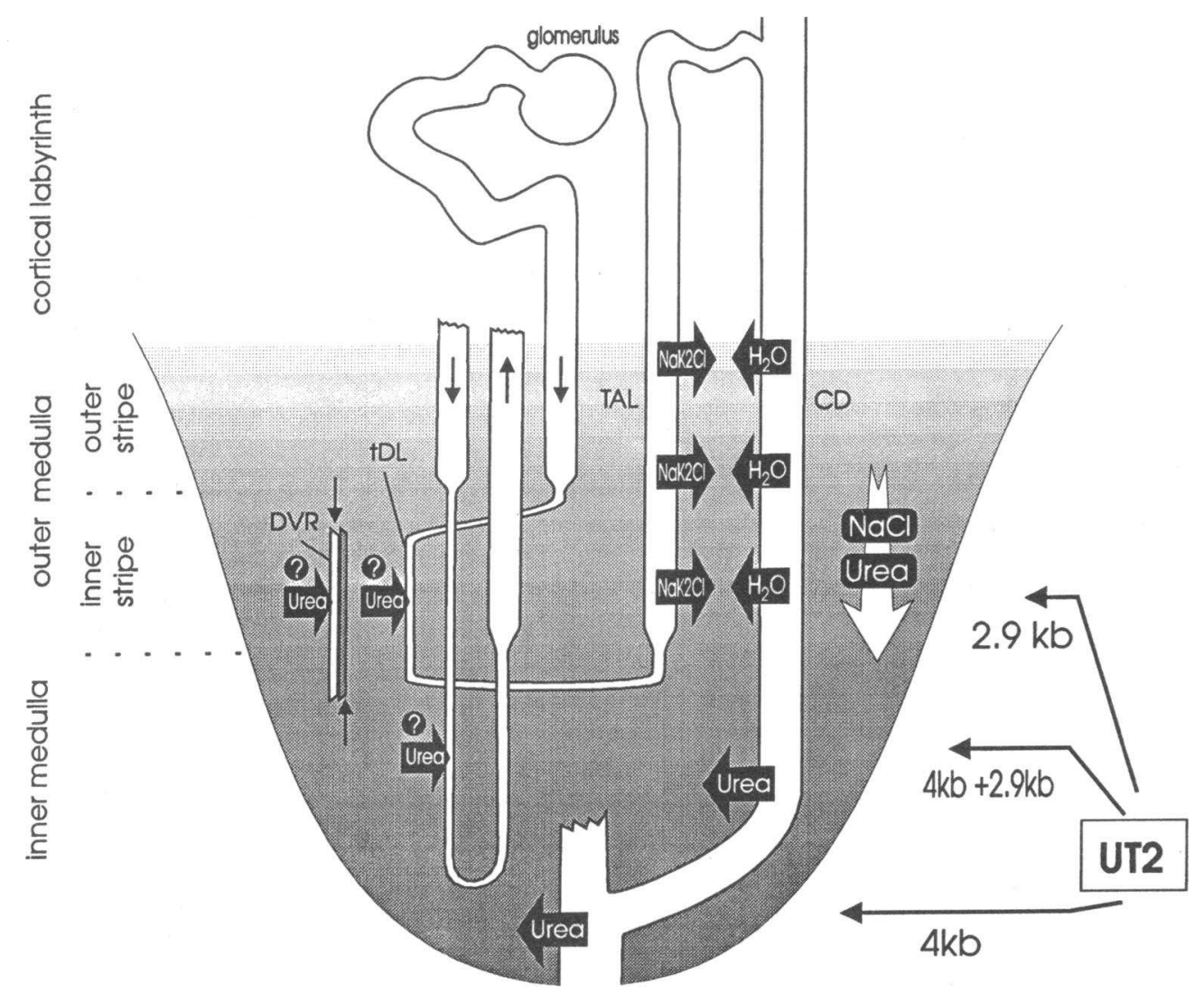

Figure 6. Schematic representation of the rat kidney to illustrate the proposed role of rUT2 in the urinary concentrating mechanism. Shown are the putative location of rUT2 and the hypothetical flow of urea during antidiuresis based on physiological and molecular data (arrows). DVR, descending vasa recta; tDL, thin descending limb; $\mathrm{TAL}$, thick ascending limb; $\mathrm{CD}$, collecting duct. The arrows to the right indicate the spatial localization of the 2.9- and 4.0-kb transcripts in the kidney medulla. It is possible that the $2.9-\mathrm{kb}$ signal in the outer medulla resides in LDL of short loops of Henle and/or in DVR. The 4.0-kb signal corresponds to the transporter shown in the outer and inner part of the IMCD. nisms will be discovered that are shared among these proteins and rUT2 which orchestrate the antidiuretic response.

It is of interest that water diuresis increased the amount of the 2.9-kb transcript in RNA isolated from the whole kidney, but not in RNA isolated from the inner medulla. This change was associated with an increase in the intensity of the hybridization signal in the ISOM. We conclude from this that the level of the $2.9 \mathrm{~kb}$ transcript increased specifically in the ISOM. This is in contrast to the response to antidiuresis where the $2.9-\mathrm{kb}$ transcript increased in both inner and outer medulla. This suggests differential segmental regulation of the 2.9-kb transcript, possibly by multiple hormones and/or due to the presence of different receptors or sensors expressed in cells of kidney inner and outer medulla.

Proposed differential regulatory mechanisms of rUT2 transcripts. Protein dietary restriction was found to cause an increase in the $4.0-\mathrm{kb}$ transcript whereas the $2.9-\mathrm{kb}$ transcript was sensitive to dehydration. This indicates that regulation of the 4.0-kb transcript is independent and distinct from that of the $2.9-\mathrm{kb}$ transcript. Thus, the protein restriction response may be primarily due to hormones, e.g., glucocorticoids, whereas the response to dehydration may be mediated by different hormones such as vasopressin. The factors which regulate the two transcripts and confer segmentally distinct responses will need to be identified as well as their mechanism of action. Moreover, like the urea cycle enzymes, two of which are regulated by transcriptional control and three by stabilization of mRNA (35), rUT2 mRNA levels may be regulated by one or both of these mechanisms.

In conclusion, rUT2 is an unusually hydrophobic, highly conserved ( $88.1 \%$ identical to rabbit UT2), structurally unique transporter which plays a central role in the urinary concentrating mechanism and regulation of nitrogen balance. Its pattern of tissue distribution is species specific and probably associated with the protein content of the diet. rUT2 mRNA is extremely responsive to changes in the physiological state of the animal and the pattern of the responses are specific to the functional state of the kidney. This regulation at the mRNA level is in contrast to that of other transporters such as intestinal and renal $\mathrm{Na}^{+}$/glucose cotransporters which are regulated primarily at the translational or posttranslational levels (39). The 2.9- and 4.0-kb transcripts of rUT2 are independently regulated and their message levels most likely are controlled by multiple factors. In conjunction with future localization of rUT2 in the kidney inner and outer medulla, these data will lead to a better understanding of the dynamics and regulation of renal urea reabsorption and urinary concentration.

\section{Acknowledgments}

C.P. Smith is a National Kidney Foundation fellow and W.-S. Lee is a Juvenile Diabetes Foundation International fellow. J.M. Sands performed this work during tenure of an Established Investigatorship from American Heart Association. This work was supported by National Institute of Health grants R29-DK41707 and R01-DK45688 to J.M. Sands and RO1-DK707844 to M.A. Hediger.

\section{References}

1. Marsh, D. J., and M. A. Knepper. 1992. Renal handling of urea. In Renal Physiology. E. E. Windhager, editor. Oxford University Press, Oxford. 13171347.

2. Knepper, M. A., R. A. Danielson, G. M. Saidel, and K. H. Johnston. 1975. 
Effects of dietary protein restriction and glucocorticoid administration on urea excretion in rats Kidney Int. 8:303-315.

3. Schmidt-Nielsen, B., J. M. Barrett, B. Graves, and B. Crossley. 1985. Physiological and morphological responses of the rat kidney to reduced dietary protein. Am. J. Physiol. 248:F31-F42.

4. Peil, A. E., H. Stolte, and B. Schmidt-Nielsen. 1990. Uncoupling of glomerular and tubular regulation of urea excretion in rat. Am. J. Physiol. 258:F1666F1674.

5. Schmidt-Nielsen, B. 1958. Urea excretion in mammals. Physiol. Rev. 32:139-168.

6. Lassiter, W. E., M. Mylle, and C. W. Gottschalk. 1966. Micropuncture study of urea transport in rat renal medulla. Am. J. Physiol. 210:965-970.

7. Isozaki, T., J. W. Verlander, and J. M. Sands. 1993. Low protein diet alters urea transport and cell structure in the rat initial inner medullary collecting duct. J. Clin. Invest. 92:2448-2457.

8. Ullrich, K. J., G. Rumrich, and B. Schmidt-Nielsen. 1967. Urea transport in the collecting duct of rats on normal and low protein diet Pflugers Arch. 295:147-156.

9. Danielson, R. A., B. Schmidt-Nielsen, and C. Hohberger. 1970. Micropuncture study of the regulation of urea excretion by collecting ducts in rats on high and low protein diets. In Urea and the Kidney. B. Schmidt-Nielsen and D. W. S. Kerr, editors. Excerpta Medica, Amsterdam. 375-384.

10. Isozaki, T., A. G. Gillan, C. F. Swanson, and J. M. Sands. 1994. Protein restriction sequentially induces new urea transport processes in rat initial IMCD. Am. J. Physiol. 266:F756-F761.

11. Sands, J. M., H. Nonoguchi, and M. A. Knepper. 1987. Vasopressin effects on urea and $\mathrm{H}_{2} \mathrm{O}$ transport in inner medullary collecting duct subsegments. $\mathbf{A m}$. J. Physiol. 253:F823-F832.

12. Gamba, G., A. Miyanoshita, M. Lombardi, J. Lytton, W.-S. Lee, M. A. Hediger, and S. C. Hebert. 1994. Molecular cloning, primary structure and characterization of two members of the mammalian electroneutral sodium-(potassium)chloride cotransporter family expressed in kidney. J. Biol. Chem. 269:1771317722 .

13. Sands, J. M., and J. P. Kokko. 1990. Countercurrent system. Kidney Int. 38:695-699.

14. Roy, D. R., H. E. Layton, and R. L. Jamison. 1992. Countercurrent mechanism and its regulation. In The Kidney: Physiology and Pathophysiology. D. W. Seldin and G. Giebisch, editors. Raven Press, Ltd. New York. 1649-1692.

15. Chou, C. L., and M. A. Knepper. 1989. Inhibition of urea transport in inner medullary collecting duct by phloretin and urea analogues. Am. J. Physiol. 257:F359-F365.

16. Pallone, T. L., J. Work, R. L. Mayers, and R. L. Jamison. 1994. Transport of sodium and urea in outer medullary descending vasa recta. J. Clin. Invest. 93:212-222.

17. Pallone, T. L. 1994. Characterization of the urea transporter in outer medullary descending vasa recta. Am. J. Physiol. 267:R269-R267.

18. You, G., C. P. Smith, Y. Kanai, W.-S. Lee, M. Stelzner, and M. A. Hediger. 1993. Cloning and characterization of the vasopressin-regulated urea transporter. Nature (Lond.). 365:844-847.

19. Olives, B., P. Neau, P. Bailly, M. A. Hediger, G. Rousselet, J.-P. Cartron, and P. Ripoche. 1994. Cloning and functional expression of a urea transporter from human bone marrow cells. J. Biol. Chem. 269:31649-31652.

20. Hediger, M. A., M. J. Coady, S. I. Tyson, and E. M. Wright. 1987.
Expression cloning and cDNA sequencing of the $\mathrm{Na}^{+}$/glucose co-transporter. Nature (Lond.). 330:370-381.

21. Wells, R. G., A. M. Pajor, Y. Kanai, E. Turk, E. N. Wright, and M. A Hediger. 1992. Cloning of a human kidney cDNA with similarity to the sodiumglucose cotransporter. Am. J. Physiol. 263:F459-F465.

22. Sands, J. M., and D. C. Schrader. 1990. Coordinate response of renal medullary enzymes regulating net sorbitol production in diuresis and antidiuresis. J. Am. Soc. Nephrol. 1:58-65.

23. Kanai, Y., M. G. Stelzner, W.-S. Lee, R. G. Wells, D. Brown, and M. A Hediger. 1992. Expression of mRNA(D2) encoding a protein involved in amino acid transport in S3 proximal tubule. Am. J. Physiol. 263:F1087-F1093.

24. Fushimi, K., S. Uchida, Y. Hara, Y. Hirata, F. Marumo, and S. Sasaki. 1993. Cloning and expression of apical membrane water channel of rat kidney collecting tubule Science (Wash. DC). 361:549-552.

25. Knepper, M. A., and F. C. Rector, Jr. 1991. Urinary concentration and dilution. In The Kidney. B. M. Brenner and F. C. Rector, Jr., editors. W. B Saunders Co., Philadelphia, 445-482.

26. Moran, B. J., and A. A. Jackson. 1989. 15N-urea metabolism in the functioning human colon: luminal hydrolysis and mucosal permeability. Gut. 31:454-457.

27. Langran, M., B. L. Moran, J. L. Murphy, and A. A. Jackson. 1992 Adaptation to a diet low in protein: effect of complex carbohydrate upon urea kinetics in normal man. Clin. Sci. 82:191-198.

28. Chou, C. L., J. M. Sands, H. Nonoguchi, and M. A. Knepper. 1990 Concentration dependence of urea and thiourea transport in rat inner medullary collecting duct. Am. J. Physiol. 258:F486-F494.

29. Toon, M. R., and A. K. Solomon. 1991. Transport parameters in the human red cell membrane: solute-membrane interactions of amides and ureas. Biochim. Biophys. Acta. 1063:179-190.

30. Cowan, S. W., T. Schirmer, G. Rummel, M. Steiert, R. Ghosh, R. A Pauptit, J. N. Jansonius, and J. P. Rosenbush. 1992. Crystal structures explain functional properties of two E. coli porins. Nature (Lond.). 358:727-733.

31. Star, R. A. 1990 . Apical membrane limits urea permeation across the rat inner medullary collecting duct. J. Clin. Invest. 86:1172-1178.

32. Imai, M., M. Hayashi, and M. Akari. 1984. Functional heterogeneity of the descending limbs of Henle's loop Plugers Arch. 402:393-401.

33. Watford, M., N. Vincent, Z. Zhan, J. Fannelli, T. Kowalski, and Z. Kovacevic. 1994. Transcriptional control of rat hepatic glutaminase expression by dietary protein level and starvation. J. Nutr. 124:493-499.

34. Meijer, A. J., W. H. Lamers, and A. F. M. Chamuleau. 1990. Nitrogen metabolism and ornithine cycle function. Physiol. Rev. 70:701-748.

35. Ulbright, C., and P. J. Snobgrass. 1992. Coordinate induction of the urea cycle enzymes by glucagon and dexamethasone is accomplished by three different mechanisms. Arch. Biochem. Biophys. 301:237-243.

36. Nielsen, S., S. R. DiGiovanni, E. I. Christensen, and M. A. Knepper. 1993. Cellular and subcellular immunolocalization of vasopressin-regulated water channel in rat kidney. Proc. Natl. Acad. Sci. USA. 90:11663-11667.

37. DiGiovanni, S. R., S. Nielsen, E. I. Christensen, and M. A. Knepper 1994. Regulation of collecting duct water channel expression by vasopressin in Brattleboro rat. Proc. Natl. Acad. Sci. USA. 91:8984-8989.

38. Burg, M. B., and A. G. Garcia-Perez. 1992. How tonicity regulates gene expression. J. Am. Soc. Nephrol. 3:121-127.

39. Hediger, M. A., and D. B. Rhoads. 1994. Molecular physiology of sodiumglucose transport. Physiol. Rev. 74:993-1026. 